\title{
Causes and consequences of Agricultural land losses of Rajshahi District, Bangladesh.
}

\author{
Md. Rahedul Isalm \\ Department of Geography, Environment and Urban Planning, Pabna University of Science and Technology \\ Pabna-6600, Bangladesh
}

\begin{abstract}
Rajshahi District is a small but it bears a huge population, resulting in a very high density of population and very high intensity of land and resource use. Per capita land is estimated to be only about $0.0526 \mathrm{ha}$. Two significantly prominent phenomena driving district's overall scenario of economic development and environment imbalance include: (a) the high growth rate of population engulfing precious land for settlement and (b) scarcity of land for ever increasing demand of food. As a result, the land is using very intensively of this District. Every year the district is losing $0.47 \%$ arable land due to the population growth and its infrastructure development. This study was conducted on Rajshahi District where the major focus was to see the causes of agricultural land losses and its consequences on environment. For analyses primary data through PRA techniques were used and secondary data were collected from published and unpublished data regarding crop, population and other ambient information from mostly government sources. Results show that the causes of agricultural land losses diversified and its consequences also multi-dimensional. If proper steps would not taken the district faces environmental hazards near future.
\end{abstract}

Key words: Agricultural land, Causes, Consequences, PRA, Rajshahi.

\section{Introduction}

According to population, Rajshahi District is one of the largest populated districts of Bangladesh but smallest one according to area. Rajshahi District is a newly industrial arena and the rate of population growth is very high $(1.34 \%)$. As its area is restricted so the basic requirements of the people have to maintain by the limited land area of the District. Hasty growth rate of population is responsible for rapid expansion of infrastructures. Fast growing rate of infrastructures causes of losses of agricultural land. Every year almost one percent of its arable land loses in this District. The arable land decreasing day by day but population is increasing rapidly. Despite the remarkable achievement in controlling the high birth rate, the population continues to grow each year because of the large existing population base (Mahabub, IRRI). Every year about $0.46 \%$ of total agricultural land is losing in Rajshahi district. If this rate is not control or the losing rate constant or increases than the agricultural land of Rajshahi district will losses quietly with in 2228 A.D. So, it's very important to find out the causes of agricultural land losses and take proper step to protect this losing rate. This study's insertion is found out its causes and consequences of agricultural land losses.

\section{Problem identification}

Rajshahi District has been passing through a hasty process of urbanization and population growth since the last few decades. Rapid growth of population, unplanned urbanization, industrialization and agricultural modernization in the outer periphery area of this district city has created pressure on the agricultural land and as well as environment. The area has been experiencing hasty changes in land use pattern especially the agricultural land decreasing rapidly and various environmental problems occurred. Remarkable changes have been occurred in agricultural land use type in study area. In 1977 the total area of agricultural and was 45950.17 acre and in 2010 it becomes 394986.32 acre. The agricultural lands have been loosed 4.57\% from 1977 to 1990 at the rate of 0.36 per year. During 1990 to 2010 at have been decreased $11.03 \%$ that's $0.55 \%$ per year. The agricultural land have been decreased $14.05 \%$ which $0.43 \%$ per year (Islam and Hassan, 2011). This study is conducted for find out the causes and consequences of the huge losses of arable land.

\section{Geographical location of the study area}

The spatial extent of this study is between 2412 to $2412 \mathrm{~N}$ latitude and 8815 to $8850 \mathrm{E}$ longitude, which belongs to Rajshahi District of Bangladesh. Its covers an area of $2407 \mathrm{sq} . \mathrm{km}$, is bounded by Naogaon District to the North, Natore District to the East, Chapai Nawabgong District to the West and the the river Padma to the South (Fig. 1). Its commonly known as "Barriad Track". It consist of 9 upazilas, 4 Thanas, 13 Municipalities, 147 Wards, 297 Mahallas, 70 union parishads, 1678 Mouzas and 1858 villages (Banglapedia 2010). Under Kopen climatic classification Rajshahi District has a topical wet and dry climate. The average temperature is $22-25 \mathrm{C}$ and rainfall is about $1448 \mathrm{~mm}$. Total land of the study area is 5994405 ha, where 
agricultures, Infrastructural and others constitute 394986.32 ha, 117615.42 ha and 63829.42 ha, respectively. Total population o the study area is 2833256 and population density is 1177 per sq. km (BBS 2008). In fig. 3 shows the study area.

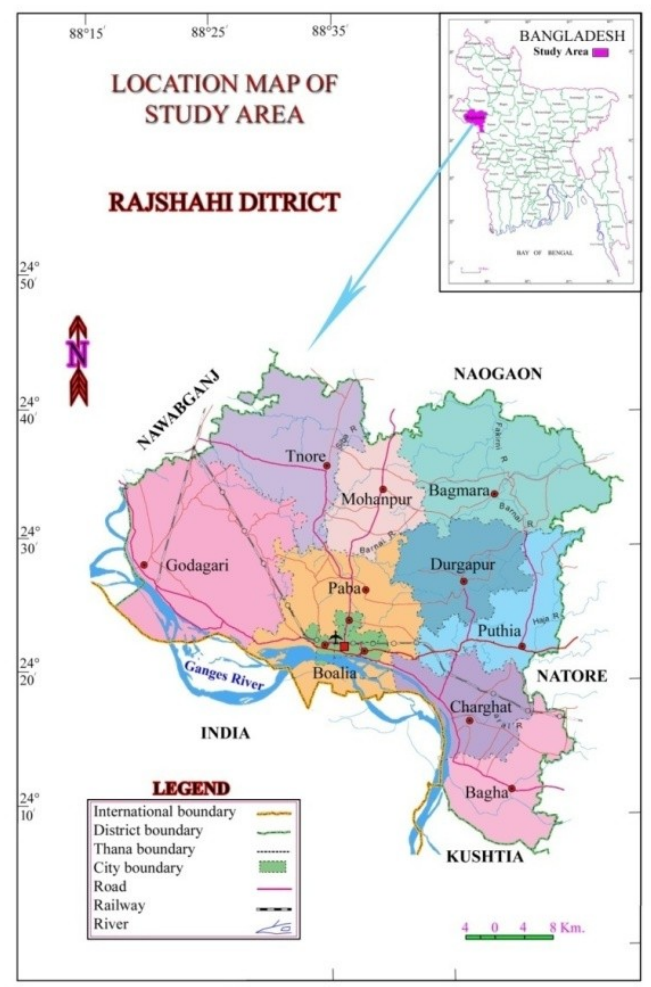

Fig- 3: Geographical location of the Study Area.

Sources: Prepared by the authors based on Banglapedia.

\section{Study Objectives, Data and the Methods}

The principal objectives of this study is to examine the causes of agricultural land losses and to find out the pressure of these losses on environment specially fertility decreasing, temperature increases, pollution, underground water level decreases, arsenic contamination, biodiversity losses and so on in Rajshahi district area in Bangladesh. To do this, several attempts has been taken for this study. First, the causes of agricultural land losses finding by participatory rapid survey (India). Second, the consequences of the agricultural land losses rate find out through the PRA method. The principal objectives and basic components of the study involve two analytical approaches: first, calculation the causes of agricultural land losses; secondly, estimation of environmental changes; and finally, the analyses jointly with the causes of agricultural land losses and its impacts on environment which indicates the consequences of agricultural land losses. The major goal of this study is to find out the causes and consequences of agricultural land losses. Based on the availability of data in Bangladesh, the primary and secondary both type data used in this study. The primary data have been collected through PRA method and the secondary data have been collected from the most the government census data and non-government Published and unpublished data. This study has selected some environmental issues as the variables which are most common scenery in the study area. This information's are mostly collected by the field survey and analyzed by using various statistical techniques.

\section{Causes of Agricultural Land Losses}

For the causes and consequences analysis PRA (Participatory Rural Appraisal) method had been followed by the PRA method the causes of agricultural land losses find out qualitatively. From the experience of local people they discussed about the causes with practical example. The causes of Agricultural land losses are shown in fig. 5. 
Source: PRA Survey 2010.

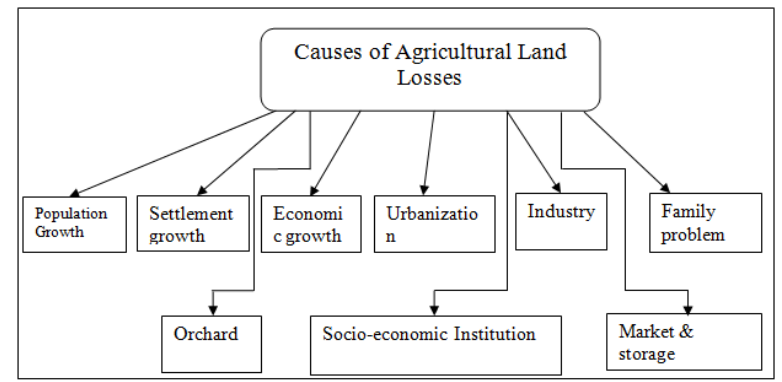

Figure 5: Causes of Agricultural land losses.

The important causes it's from PRA methods are-

\subsection{Population Growth}

Population growth is the main causes of agricultural land losses. After the liberation war in the area of recent Rajshahi district population was 746000 but now it is 2833000. A feature of population growth of Rajshahi district is given at fig. 5.1. From the discussion with local people it is clear that for the population growth the infrastructure increases and its' creates pressure on agricultural land.

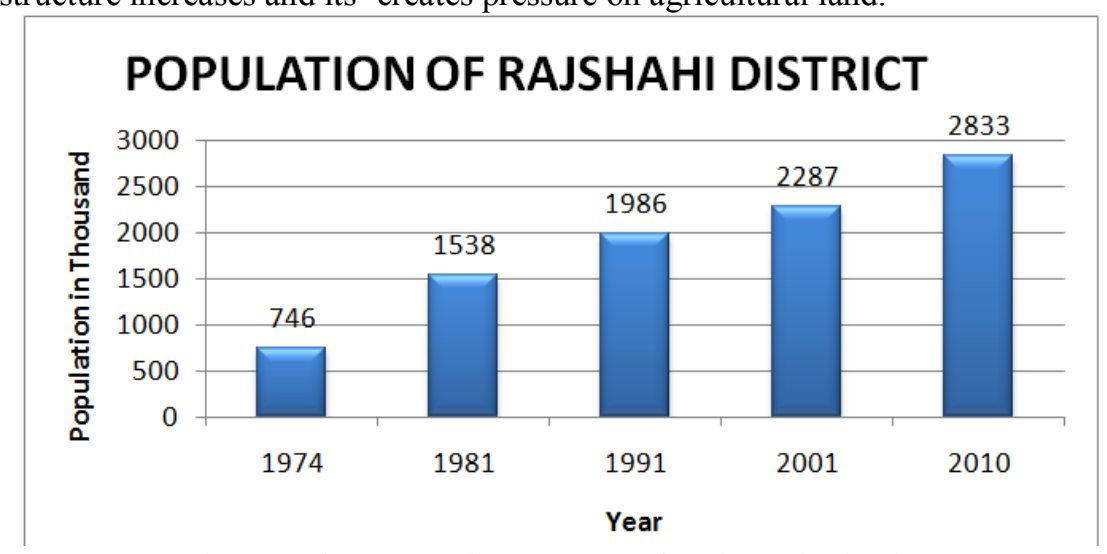

Figure 5.1: Population growth of Rajshahi District.

Source: Statistical Yearbook of Bangladesh (1978-2008)

\subsection{Infrastructural Growth}

Infrastructural growth is a causes closely related to population growth. For the extra population it's need extra infrastructure. Generally in Rajshahi district the infrastructures are following as-

\section{2. a. Settlement}

Settlement is the main infrastructure of Rajshahi district with the population growth the infrastructure build up quickly. For the fulfillment of demand of extra population every day, there are growing up more and more settlement. In the greater Rajshahi (Rajshahi, Chapainawabgong, Nator and Naogan) total settlement was 672369 at in 1974 and now only in Rajshahi district total settlements is 642554. The growing up settlement features is shown in fig. 5.2.a.

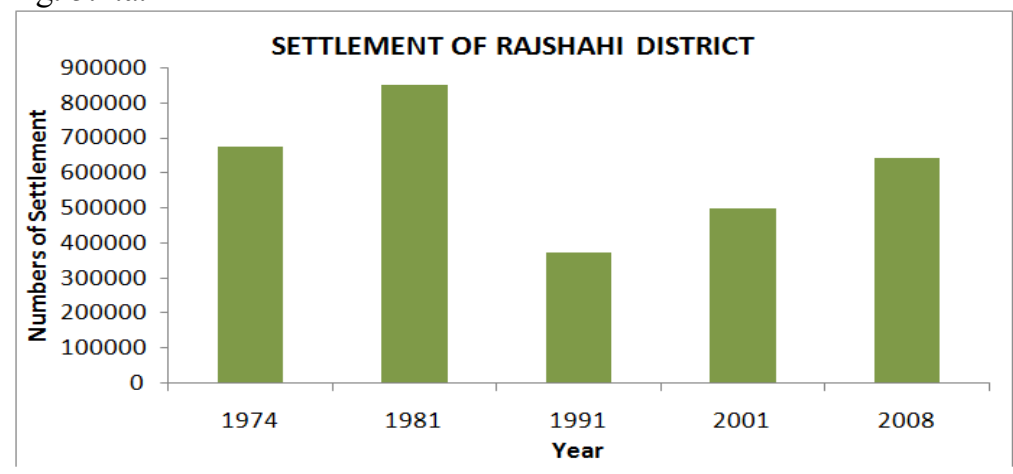

Figure 5.2.a: Settlement growth of Rajshahi District.

Source: Statistical Yearbook of Bangladesh (1978-2008) 


\section{3. b. Roads}

Road is another type of infrastructure that is one of the most important cases for agricultural land losses. After the liberation war there was $28 \mathrm{Km}$ pacca road in Rajshahi. But now it's about Km pacca road, $4726 \mathrm{Km}$ mud rood and 70km Railway. The total Road network is shown in fig. 5.3.b.

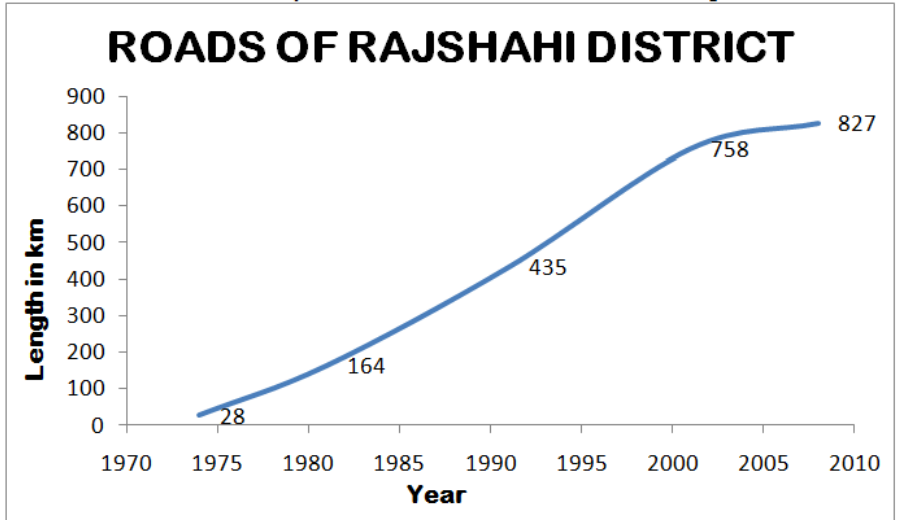

Figure 5.3.b: Roads of Rajshahi District.

Source: Statistical Yearbook of Bangladesh (1978-2008)

\section{3. c. Educational Institution}

Rajshahi is known as city of education. There is a lot of educational institution in Rajshahi. With the time it's growing more and more. For this infrastructure are growing up and the agricultural land losing. The number of educational institution is shown in fig. 5.3.c.

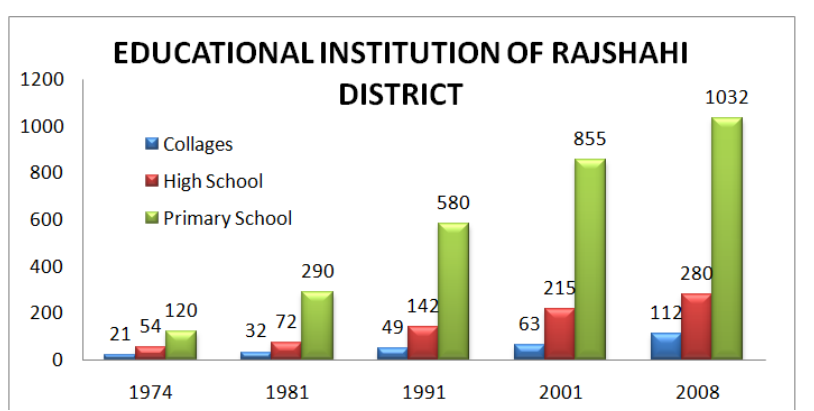

Figure 5.3.c : Educational institution of Rajshahi District.

Source: Statistical Yearbook of Bangladesh (1978-2008)

\section{3.d. Socio-economic Institution}

Among the infrastructure Socio-economic institution is the most important causes of losses agricultural land. Socio-economic institution is itself is a consumer of agriculture land and it's helps people to build up infrastructure. After the liberation war this type of institution growing up rapidly and its impacts on agricultural land. The development of socio-economic institution is shown in fig. 5.3.d.

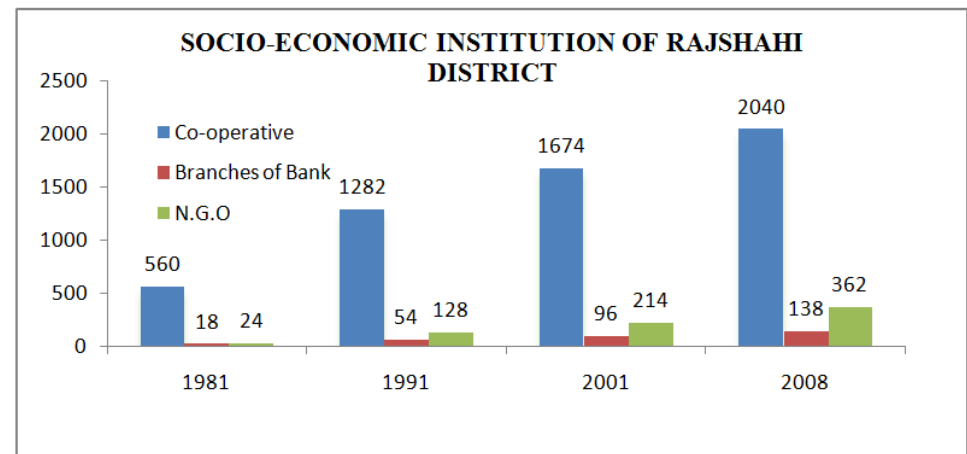

Figure 5.3.d: Socio-economic institution of Rajshahi District.

Source: Statistical Yearbook of Bangladesh (1978-2008) 


\subsection{Urbanization}

"Urbanization is a process of being urbanized by this processes professionally changed from agriculture to other and behavioral changed". (Mitched, 1998). Urbanization is such a process by this the rural area turn into urban area. For the urbanization the Agricultural land losses at a high rate. Just after the liberation war in our country, there is a great revolution in socio-economic sector and started urbanization rate. With the increases of urbanization rate, the agricultural land losses rate also increasing. In the figure 5.4 the rate of urbanization in Bangladesh and Rajshahi District is shown.

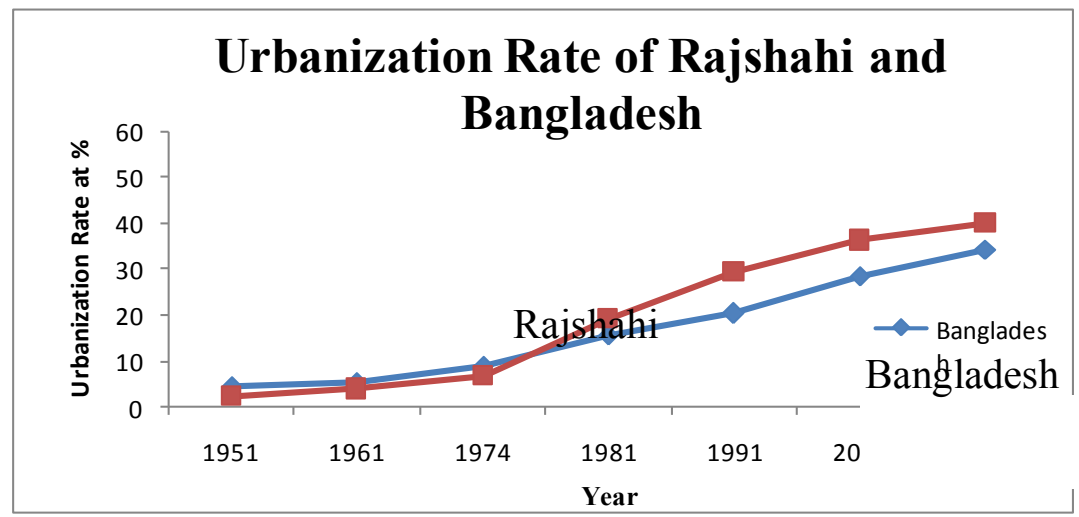

Figure 5.4: Urbanization rate of Bangladesh and Rajshahi District.

Source: Statistical Yearbook of Bangladesh (1978-2008)

\subsection{Industrialization}

From the PRA method, industrialization is another cause of losses agricultural land. The people comment that "Industrialization especially agro-industrialization like cold storage, food processing industry, store house etc is the main causes of agricultural land losses in Rajshahi District.

\subsection{Orchard}

Although Orchard is known as agriculture but it is a specialized agricultural sector. Orchard is one of the main causes of agricultural land losses. Day by Day orchards are increasing in Rajshahi district. Especially Mangoes, Lichi, Kul and other type of Orchard are growing up and grain food crops are decreasing. Increases of Orchard are shown in fig. 5.6.

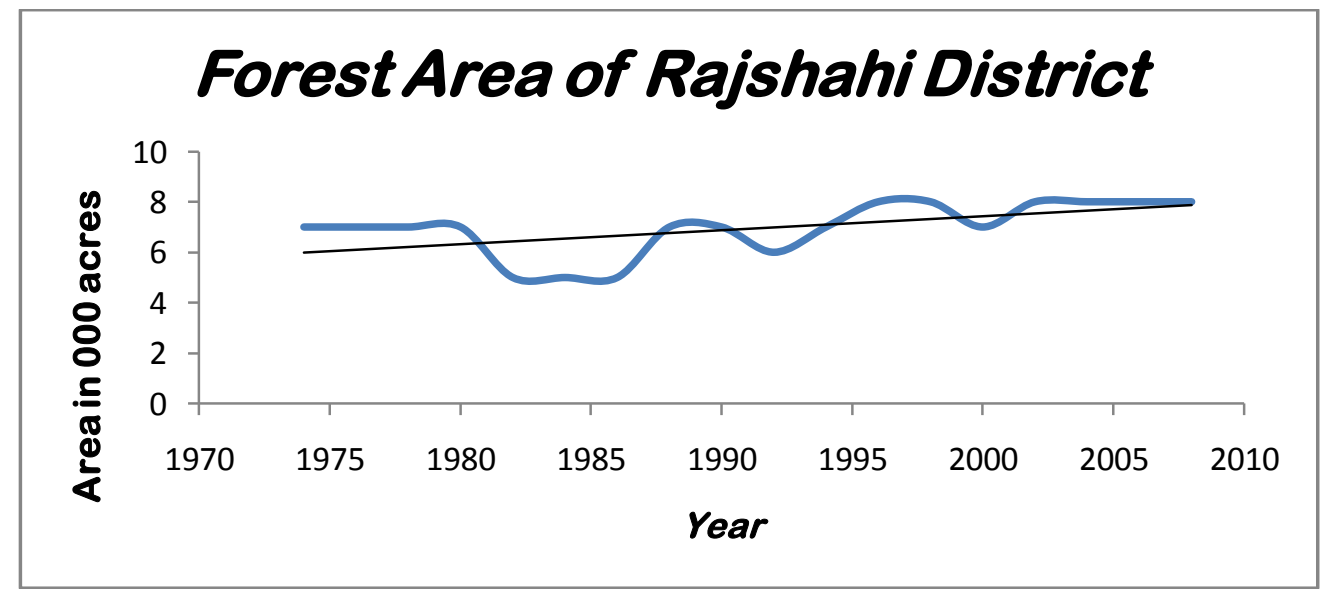

Figure 5.6: Forest area of Rajshahi District.

Source: Statistical Yearbook of Bangladesh (1978-2008)

\subsection{Economic Growth}

The economic condition of Rajshahi district is growing up better day by day. The profession is changing there are a lot of people working abroad and earns a great amount of foreign currency. For the economic growth people spent their money for better living and building up expensive house in agricultural land. This is the one of cause of agricultural land losses. 


\subsection{Family Problem}

By the PRA survey, a new thing is come out as a cause of agricultural land losses and that is family problem. The PRA member mention that with the expanded of family, the problem among the family member growing up and they divided their family. After separation the built up new houses and it's became a causes of agricultural land losses.

\subsection{Others}

Without the above causes there are a lot of causes of agricultural land losses. Among this Market place, pond, Store-house, Brick field etc. are mentionable.

\section{Consequences of Agricultural Land Losses}

There are a lot of Consequences of agricultural land losses. Among this impacts water shortage, land fertility decreasing, food crisis and so on. The impacts of Agricultural and losses are shown in fig. 6 and discuss in the following section. With the PRA survey the causes and consequences comes from the root level and this impacts are disuses in this section.

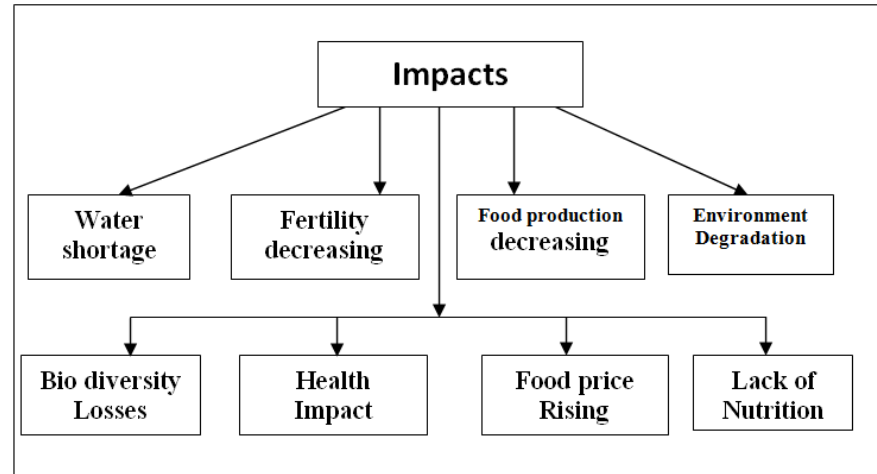

Source: PRA Survey 2010.

Figure 9: Impacts of Agricultural land losses.

\subsection{Water Shortage}

Among the impact of Agricultural land losses water shortage is the most important impact. In Rajshahi District for the mitigation of food crises farmer cultivating HYV and their land more intensively and uses more and more surface and underground water. In the recent time water shortage is burning question in the summer season. So loses of agricultural land is one of the most important causes of water shortage.

\subsection{Land Fertility Decreasing}

Land fertility is decreasing day by day in Rajshahi District. For meeting of food production decreasing due to agricultural land losses, farmer cultivating their land more intensively and uses more and more chemical fertilizer, for this causes land fertility decreasing. For intensive cultivating the net cultivated are losses but total cultivated area increases. It's show in fig. 6.2.

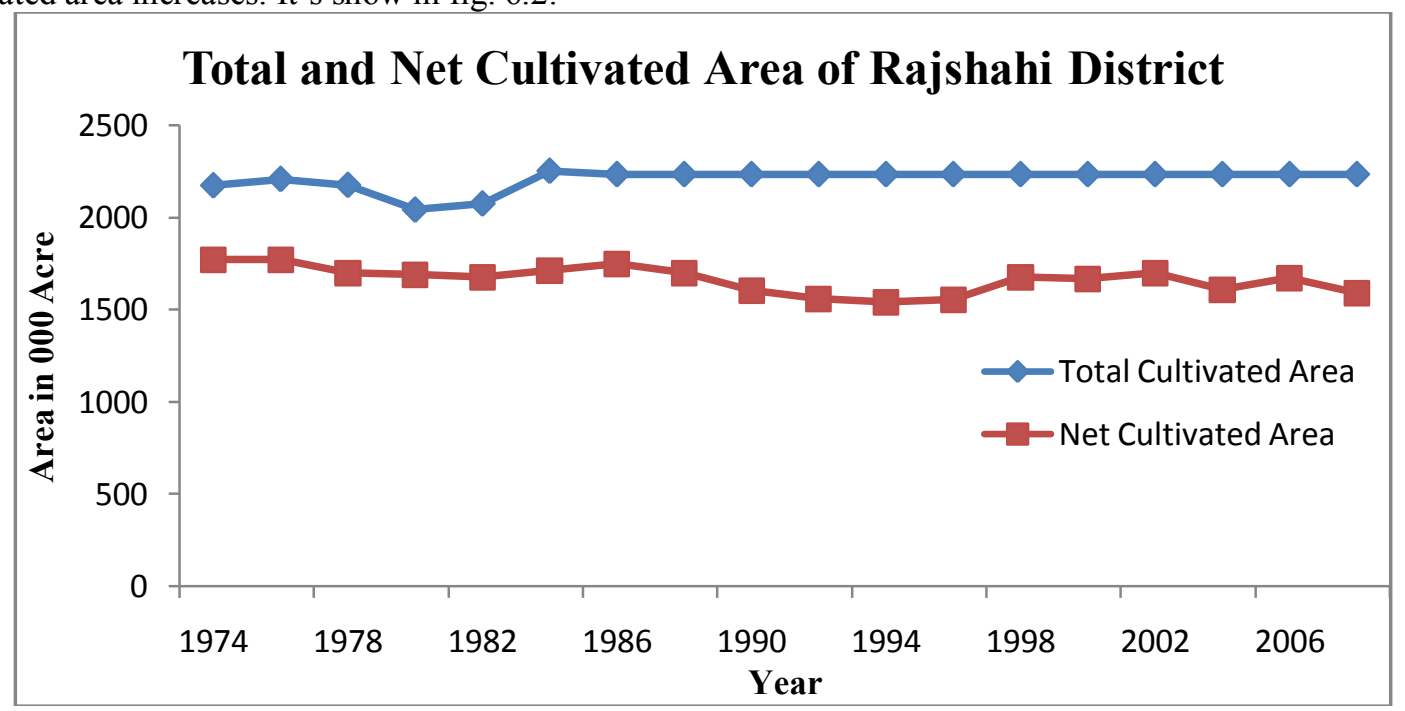

Figure 6.2: Total and Net Cultivated area of Rajshahi District. 
Source: Statistical Yearbook of Bangladesh (1978-2008)

\subsection{Food Production Decreasing}

Due to the agricultural land decreasing food production is decreasing gradually. Moreover, for losing of agricultural land food grain production and oil seeds production decreasing bit by bit.

\subsection{Environment Degradation}

Through PRA survey most of the members opinion was that for agricultural land losing the farmer cultivate their land intensively and uses chemical fertilizer, pesticide and other poisoned things for this cause water, air, land and other element of environment polluted day by day.

\subsection{Bio-diversity Losses}

Due to the losses of agricultural land, farmer cultivating HYV and increases their production. For this cause many traditional crops are almost lost their extinct. Moreover they using pesticide for their crops and this is a cause of extinction of some environment friendly faunal species.

\subsection{Food Price Rising}

Most of the PRA members mentioned that for the agricultural land losing food internal food production decreasing and Govt. importing necessary food crops and food price increasing in the market.

\subsection{Lack of Nutrition}

Due to the HYV cultivating and decreasing food diversity is creating nutrition lack among the people especially the poor and child are the sufferers of this problem.

\subsection{Health Impact}

For food production decreasing and food price increasing, farmer and business man uses more and more pesticide, chemical and other harmful elements that's directly and indirectly impacts on health.

\section{Conclusion}

With unchecked population growth and economic development in the study area, infrastructural land has increasingly expanded and encroached upon agricultural land in the last few years. In this paper analyzes the causes of agricultural land losses and determine its consequences. By using primary and secondary data integrated, it was found that causes of agricultural land losses and consequences very damaging on environment. Moreover for the loss of agricultural land it's having been creates pressure on environment and it's polluted by different ways. The food production decreasing, food price rising and land fertility decreasing and this all are the result of agricultural land losing. Infrastructural development is the main causes of agricultural land losses. Though the agricultural land of the study area have been decreasing these can be taken a land use plan. If the land is used by planning guide, the agricultural activity will be continued otherwise the agricultural land will dropout and the area will be environmentally vulnerable.

\section{References}

[1] Anderson JR. 1970. A Geography of Agriculture. WMC Brown Co., Dubuque, Iowa, USA

[2] Anderson JR, Hardy EE, Rooch JT and Witmer RE. 1976. Land Use and Land Cover Classification System for Use with Remote Sensor Data (Professional Paper 964), Reston, VA: USGS.

[3] Banglapedia 2006. National Encyclopedia of Bangladesh. Asiatic Society of Bangladesh. Genesis Printing and

[4] Packaging, Dhaka.

[5] BBS (Bangladesh Bureau of Statistics) 1978. Statistical Yearbook of Bangladesh. Ministry of Planning, Dhaka.

[6] Govt. of Bangladesh.

[7] BBS (Bangladesh Bureau of Statistics) 2002. Bangladesh Population Census, 2001. Ministry of Planning, Dhaka. Govt. of Bangladesh.

[8] BBS (Bangladesh Bureau of Statistics) 2005. Census of Agriculture, 2000. Zilla Series, Rajshahi. Bangladesh

[9] Bureau of Statistics, Dhaka, Bangladesh.

[10] BBS (Bangladesh Bureau of Statistics) 2008. Economic Review 2008. Ministry of Planning. Government of

[11] Bangladesh.

[12] Bhuiyan M. 2003. Has urbanization caused agricultural land loss? The Daily Star, November 12003.

[13] Di Gregorio CM and Jansen J. 1998. A new concept for a land cover classification system. Land 2(1): 55-58

[14] FAO (Food and Agriculture Organization) 2000. Yearbook 49: Production. Rome, Italy.

[15] Islam KN. 2000. Temporal Mapping and Spatial Analysis of Land Transformation Due to Urbanization and its Import on Surface Water System: A Case from Dhaka Metropolitan Area. Int. Arch. Photogram. Remote Sensing XXX(B7): Amsterdam.

[16] Islam R. and Hassan Z. 2011, Land use changing pattern and challenges on agricultural land: A study on Rajshahi district; Journal of life and earth science, Rajshahi university. P (69-74)

[17] Jaysal RK and Ram R. 1999. Application of remote sensing technology for land use/land cover change analysis. J. Indian Soc. Remote Sensing 27(2):

[18] Mahbub A. 2003. Agricultural land loss and food security: An assessment. IRRI, Manila, The Philippines. 
[19] Rahman MR and Saha SK. 2009. Spatial dynamics of cropland and cropping pattern changes analysis using landsat TM and IRS P6 ISSII satellite images with GIS. Geo-Spatial Info. Sci. 12: 17-21.

[20] Rahman MR, Islam AHM and Hassan MS. 2005. Change detection of winter crop coverage and the use of

[21] Landsat data with GIS. J. Geo- Environ. 4: 1-13.

[22] Ram R and Kolakar S. 1993. The Future of Our Land: Facing the Challenge. Hall of India Pvt. Ltd., New Delhi.

[23] Singh A. 1989. Digital change detection techniques using remotely sensed data. Int. J. Remote Sensing 10: 9891003.

[24] Vink RK. 1975. A framework for land evolution. www.mpl.fr/creat/tallercolumbia/FAO/AGLL/pdf.docs

[25] Yang X and Lo CP. 2000. Relative radiometric normalization performance for change detection from multi date

[26] Satellite images. Photogram. Eng. Remote Sensing 66: 967-980. 